\title{
Standardization In The Home Building Industry: An Empirical Investigation Into The Compatibility Between Accounting And Estimating Cost Codes
}

Mark D. Law, Bloomsburg University, USA

\begin{abstract}
The purpose of this study was to investigate the utilization of standardized cost codes for the estimating and accounting functions related to the scale of operations by Pennsylvania's home building contractors. Firm size was examined as to its impact on three issues in construction standardization practice: 1) the use of a standardized number system for estimating, 2) the use of a standardized number system for accounting, and 3) the use of the same standardized number system for both estimating and accounting. Significant differences existed among firm sizes regarding all three items relating to standardized cost codes - a standardized numbering system used for estimating, a standardized numbering system used for accounting, and the same standardized numbering system used for both estimating and accounting functions. Overall, however, a large percentage of Pennsylvania home building firms are behind the curve with regard to their knowledge and utilization of standardized cost codes.
\end{abstract}

Keywords: Construction, accounting, standardization, cost codes

\section{INTRODUCTION}

$\mathrm{n}$ the home building process, contractors employ a cost variance calculation to help manage and control
various jobs. The cost variance calculation is made by subtracting the actual costs from the estimated
(budgeted) costs. In order to assist in the computation of the cost variance, a job cost system should include a set of standards. Due to the fact that cost variance uses elements from two different functions - estimating and accounting - the use of standardization in the organization of information can offer a competitive advantage for a contractor. These standards, for both estimating and accounting, can help provide more accurate and reliable information for decision-support tools. Current information must be gathered to understand the practices and needs of the of Pennsylvania Home Building firms with respect to the utilization of standards. In order to attain this goal, the research question was posed to examine these standardization issues as affected by the size of the firm.

\section{PURPOSE}

The purpose of this study was to investigate the utilization of standardized cost codes for the estimating and accounting functions related to the scale of operations by Pennsylvania's home building contractors. Differences in firm size were examined as a factor in the use of a standardized number system for estimating, the use of a standardized number system for accounting, and the use of the same standardized number system for both estimating and accounting.

\section{LITERATURE REVIEW}

"Standardization is the extensive use of components, methods or processes in which there is regularity, repetition, and a background of successful practice and predictability" as defined by Gibb (2001), (p. 308). 
Standardization developed largely from a grass roots effort from a consortium of businesses and organizations. These businesses and organizations, through a democratic means and manner, cultivated their own guidelines and procedures. The concept of standardization is supported by voluntary participation through a central forum to benefit and improve all of the organization members' business processes (Bredillet, 2003). Standardization is an allencompassing business operating in a large international arena. There are over one-half million standards published throughout the globe. These numbers only account for the external standards. The number of standards grows substantially when factoring in internal standards of businesses and organizations (Bredillet, 2003).

Standardization has been employed in the field of construction in one form or another for a long period of time. Bricks and dimensional lumber, for example, in their simplest form, were standardized components of the early building industry. In the early 1900s, there was a movement from some prominent architects who entertained the notion of introducing scientific methods of mechanization and industrialization of components into the building process. They argued about the shortcomings of craft production and its antediluvian model based on a Medieval Ages mindset and approach to construction trade (Gann, 1996). Standardization has seen plenty of changes over the years especially in regard to the implementation of standard components and processes. However, one issue remains the same: the balancing act between standardization and customization. The essential issue is not only to harmonize the balance between the standardization of products, procedures, and processes for efficiency and cost savings but also to preserve the flexibility in building and design to make certain consumers have customizable options for their buildings (Gibb \& Isack, 2001).

The use of standards in the management of construction projects is a significant factor in developing skills and proficiencies and aiding in economic development. Standards are seen as a medium for managing construction practices more efficiently and effectively by fostering improved utilization of available resources (Bredillet, 2003). The streamlining of the construction processes and procedures can facilitate the improvement and progression of projects, improve recording keeping, reduce waste, repair, and rework, and increase the overall productivity of the organizations (Gibb, 2001).

Over time there have been many critics and opponents of standardization in the construction industry. Some authors have been raised concerns about the nature of construction and certain aspects of the industry that are impediments to standardization. Industry fragmentation, altering work site conditions due to weather, changing work environments, and other unforeseen problems are seen by some as deterrents in the industry. The argument, in general terms, revolves around the assumption that the construction industry by nature is not conducive to quantitative measurement. Opponents also argue about increasing bureaucracy in the form of paperwork and management, reducing flexibility in operation, and suffocating innovation (Moatazed-Keivani, 1999; Kumaraswamy $\&$ Dissanayaka, 2000). However, Gibb (2001) states, "contemporary business systems, information technology and management techniques enabled standardized processes to be more sophisticated than have previously been the case, thus addressing historical concern about inappropriate, bureaucratic procedural standardization" (p. 313).

One of the main goals of a construction project is to complete the project on time and within budget. In pursuit of this goal, a unified effort is required during the construction process (Miller, 2001). Paulson (1995) states that "integrated management control systems are designed to reflect the interdependence of estimating, cost control, scheduling, materials management, and other systems" (p. 455). One essential ingredient that can facilitate this process is the integration of the estimating and accounting functions through the employment of a common numbering system.

According to Gibb (2001), "standardization works by ensuring accurate fit and interchangeability of components. Thus the most important area for standardization is actually the interfaces between the components rather than the components themselves" (p. 308). Research done by Miller (2001) has shown that incorporating standardized codes by a commercial contractor can increase productivity when the codes are transferable and comparable between the estimating and accounting systems (Miller, 2001). The findings by Miller (2001) supported research by Spence (1990), which showed the benefits of an integrated project numbering system for large projects. The benefits listed from Spence in Miller (2001) were "increased analysis capabilities, shortened data input time, reduced errors and staffing requirements, and increased information available to management" (p. 72). These studies showed the importance of the utilization of standardized cost codes. 
Unfortunately, there is frequently no relationship between the numbering codes used in the estimating system and the numbering codes used in the accounting system by most contractors (Miller, 2001). While accounting codes and estimating costs codes are very important aspects of the management function of a construction project, they are seldom interchangeable. In fact, estimating and accounting structures are quite different in many fields of operations. These differences are largely attributable to their origins (Miller, 2001). Accounting systems codes were developed by accountants and often based on a manufacturing system. Estimating codes, in contrast, were designed by cost engineers and professional organizations to meet the needs of project managers for monitoring and reporting on the project. This dissimilarity of codes results in incompatibility that revolves around codes developed by two separate professions: accountants and cost engineers (Paulson, 1995).

In today's construction climate, there is increased competition at both the local and the global level because of the trend towards globalization. It is important that a system is in place in construction organizations to ensure quality in procedures, products, and processes. In general, the use of standards can improve and bring about a competitive edge to an organization by providing a mechanism to improve management control, increase communication and awareness, and enhance records and information (Salem Hiyassat, 2000). A study from the CIRIA (Construction Industry Research and Information Association) examined the value gain from the use of standards. One section of the study focused on the adoption of systematic standardized procedures. According to Gibb (2001), "the report concludes that deliberate, systematic use of standards started early in the process, will add value to projects by increasing predictability and efficiency and overcome some of the costly unpredictabilities" (p. 308).

\section{RESEARCH QUESTION}

To what extent are the differences in the utilization of standardized cost codes for the estimating and accounting functions related to the scale of operations?

\section{DATA}

The population of this study consisted of home building firms in the state of Pennsylvania. As to the researcher's knowledge, no single list exclusive to Pennsylvania home building firms existed. Subsequently, the researchers of the study implemented a cluster approach through a multi-stage sampling technique as a means to collect data. In the final phase of the area probability sampling technique, a list of Pennsylvania home building firms, from the sampled counties, was compiled. Responding firms were than classified into three areas: small, medium, and large based on the use three indicator variables: number of employees, home output per year, and annual revenue.

\section{RESULTS}

Table 1: Standardized Cost Code Practices Examined by Firm Size

\begin{tabular}{lccccccc}
\hline & & \multicolumn{7}{c}{ Mean } & & \\
\cline { 3 - 6 } Cost codes & $\mathrm{n}$ & Small & Medium & Large & Total & $F$ & $p$ \\
\hline $\begin{array}{l}\text { Standardardize numbering } \\
\text { system used for estimating }\end{array}$ & 359 & 1.71 & 2.18 & 3.08 & 2.32 & 57.322 & $<.001$ \\
$\begin{array}{l}\text { Standardardize numbering } \\
\text { system used for accounting }\end{array}$ & 359 & 2.19 & 3.12 & 3.95 & 3.08 & 35.169 & $<.001$ \\
$\begin{array}{l}\text { Same standardardize } \\
\text { numbering system used for } \\
\text { both estimating and }\end{array}$ & 359 & 1.79 & 2.64 & 3.37 & 2.59 & 30.689 & $<.001$ \\
accounting & & & & & & & \\
\hline
\end{tabular}

Note. Application Scale: 1 = Never; $2=$ Seldom; $3=$ Sometimes $; 4=$ Most Times $; 5=$ Always 
In order to answer the research question, three survey items were used to gauge the home builder's use of standardized cost codes in regard to their firms estimating and accounting practices. In order to examine the use of standardized cost codes by firm size, one-way analysis of variance (ANOVA) and Tukey multiple comparison tests were utilized. First, the one-way analysis of variance (ANOVA) was performed. Table 1 shows the statistical results of the one-way analysis of variance (ANOVA) for survey item numbers nine, ten, and eleven based on firm size regarding the use of standardized cost codes.

The data reveal that there are significant differences based on firm size on the use of a standardized number system for estimating $(\mathrm{F}=57.322 ; \mathrm{p}<.001)$, the use of a standardized number system for accounting $(\mathrm{F}=35.169 ; \mathrm{p}$ $<.001)$, and the use of the same standardized number system for both estimating and accounting $(\mathrm{F}=30.689 ; \mathrm{p}$ $<.001)$ by Pennsylvania home building firms.

Secondly, a post hoc analysis was performed. A Tukey multiple comparison test was utilized to examine differences between the individual firm sizes; small, medium, and large as illustrated in Table 2. The post hoc results for the use of a standardized number system for estimating showed $\mathrm{s}=\mathrm{m}(\mathrm{p}=.058) ; \mathrm{s}<1(\mathrm{p}<.001) ; \mathrm{m}<1(\mathrm{p}$ $<.001)$. The use of a standardized number system for accounting showed $\mathrm{s}<\mathrm{m}(\mathrm{p}<.001) ; \mathrm{s}<1$ ( $\mathrm{p}<.001) ; \mathrm{m}<1$ (p $<.001)$. The last item, the use of the same standardized number system for both estimating and accounting showed $\mathrm{s}$ $<\mathrm{m}(\mathrm{p}<.001) ; \mathrm{s}<1(\mathrm{p}<.001) ; \mathrm{m}<1(\mathrm{p}=.001)$.

Table 2: Post Hoc Standardized Cost Code Practices Examined Between Firm Size

\begin{tabular}{|c|c|c|c|c|c|c|c|}
\hline \multirow[b]{2}{*}{ Cost codes } & \multirow{2}{*}{$\begin{array}{c}\text { Size } \\
\text { Class } \\
\end{array}$} & \multirow{2}{*}{$\begin{array}{c}\text { Size } \\
\text { Class } \\
\end{array}$} & \multirow{2}{*}{$\begin{array}{l}\text { Mean } \\
\text { Differ }\end{array}$} & \multirow{2}{*}{$\begin{array}{c}\text { Standard } \\
\text { Error }\end{array}$} & \multirow[b]{2}{*}{ Sig. } & \multicolumn{2}{|c|}{$\begin{array}{c}95 \% \text { Confidence } \\
\text { Level }\end{array}$} \\
\hline & & & & & & Lower & Upper \\
\hline \multirow{6}{*}{$\begin{array}{l}\text { Standardardize numbering } \\
\text { system used for estimating }\end{array}$} & \multirow[t]{2}{*}{ small } & medium & -0.470 & 0.206 & 0.058 & -0.96 & 0.01 \\
\hline & & large & -1.370 & 0.207 & $<.001$ & -1.85 & -0.88 \\
\hline & \multirow[t]{2}{*}{ medium } & small & 0.470 & 0.206 & 0.058 & -0.01 & 0.96 \\
\hline & & large & -0.890 & 0.208 & $<.001$ & -1.38 & -0.40 \\
\hline & \multirow[t]{2}{*}{ large } & small & 1.370 & 0.207 & $<.001$ & 0.88 & 1.85 \\
\hline & & medium & 0.890 & 0.208 & $<.001$ & 0.40 & 1.38 \\
\hline \multirow{6}{*}{$\begin{array}{l}\text { Standardardize numbering } \\
\text { system used for accounting }\end{array}$} & \multirow[t]{2}{*}{ small } & medium & -0.930 & 0.210 & $<.001$ & -1.42 & -0.44 \\
\hline & & large & -1.760 & 0.210 & $<.001$ & -2.26 & -1.27 \\
\hline & \multirow[t]{2}{*}{ medium } & small & 0.930 & 0.210 & $<.001$ & 0.44 & 1.42 \\
\hline & & large & -0.830 & 0.211 & $<.001$ & -1.33 & -0.33 \\
\hline & \multirow[t]{2}{*}{ large } & small & 1.760 & 0.210 & $<.001$ & 1.27 & 2.26 \\
\hline & & medium & 0.830 & 0.211 & $<.001$ & 0.33 & 1.33 \\
\hline \multirow{6}{*}{$\begin{array}{l}\text { Same standardardize } \\
\text { numbering system used for } \\
\text { both estimating and } \\
\text { accounting }\end{array}$} & \multirow[t]{2}{*}{ small } & medium & -0.850 & 0.202 & $<.001$ & -1.33 & -0.38 \\
\hline & & large & -1.590 & 0.203 & $<.001$ & -2.06 & -1.11 \\
\hline & \multirow[t]{2}{*}{ medium } & small & 0.850 & 0.202 & $<.001$ & 0.38 & 1.33 \\
\hline & & large & -0.730 & 0.204 & 0.001 & -1.21 & -0.25 \\
\hline & \multirow[t]{2}{*}{ large } & small & 1.590 & 0.203 & $<.001$ & 1.11 & 2.06 \\
\hline & & medium & 0.730 & 0.204 & 0.001 & 0.25 & 1.21 \\
\hline
\end{tabular}

Note. Application Scale: $1=$ Never; $2=$ Seldom; $3=$ Sometimes; $4=$ Most Times; $5=$ Always 


\section{CONCLUSIONS}

Three survey questions were utilized to address the research question. The questions were designed to address the home builders' utilization of standardized cost codes in regard to their estimating and accounting functions. The survey questions dealt with the use of the three items: 1) a standardized numbering system used for estimating, 2) a standardized numbering system used for accounting, and 3) the same standardized numbering system used for both estimating and accounting functions by home builders. The researcher found that significant differences existed among firm sizes regarding all three items relating to standardized cost codes - a standardized numbering system used for estimating $(\mathrm{p}<.001)$, a standardized numbering system used for accounting $(\mathrm{p}<.001)$, and the same standardized numbering system used for both estimating and accounting functions $(\mathrm{p}<.001)$.

Additionally, post hoc analysis was performed to test differences for these three items between firm sizes. First, when comparing small firm size to medium firm size, the data revealed that there were significant differences for two items: 1) a standardized numbering system used for accounting $(\mathrm{p}<.001)$ and 2$)$ the same standardized numbering system used for both estimating and accounting functions $(\mathrm{p}<.001)$. However, no significant differences existed for a standardized numbering system used for estimating $(\mathrm{p}=.058)$ between these two sizes. Secondly, when comparing small firm size to large firm size, there were significant differences between small firms and large firms for all three items examined. The data revealed that small firms used a standardized numbering system for estimating ( $\mathrm{p}<.001)$, a standardized numbering system for accounting $(\mathrm{p}<.001)$, and the same standardized numbering system used for both estimating and accounting functions $(\mathrm{p}<.001)$ less than large firms. Finally, when comparing medium firm size to large firm size, there were significant differences between medium firms and large firms for all three items examined. The data revealed that medium firms use a standardized numbering system for estimating ( $\mathrm{p}<.001)$, a standardized numbering system for accounting $(\mathrm{p}<.001)$, and the same standardized numbering system used for both estimating and accounting functions $(\mathrm{p}=.001)$ less than large firms.

The research question was designed to address the home builders' utilization of standardized cost codes in regard to their estimating and accounting functions. Three survey items were utilized to address the research question. The survey questions dealt with the use of three items: 1) a standardized numbering system used for estimating, 2) a standardized numbering system used for accounting, and 3) the same standardized numbering system used for both estimating and accounting functions by home builders.

The data illustrated that there are significant differences in the utilization of standardized cost codes for the estimating and accounting functions among firm sizes by Pennsylvania home builders. Overall, while significant differences exist among firm sizes, the implementation of standards is under-utilized in the Pennsylvania home building industry. The implementation of standards is an area where many firms are not taking advantage of opportunities to increase efficiency and productivity in their businesses. The use of standards in the day-to-day operations has been shown to enhance management decisions by providing accurate and timely information and improved utilization of existing resources. As illustrated by Gibb (2001), the streamlining of the construction processes and procedures can facilitate the improvement and progression of projects, improve recording keeping, reduce waste, repair, and rework, and increase the overall productivity of the organizations.

With the increasing advances in information technology for both the estimating and accounting software, the practices of the estimating and accounting functions are becoming more sophisticated. The use of standardized cost codes can facilitate the process and make home building firms more competitive by increasing efficiency and effectiveness of the management process. Furthermore, standards provide a vehicle in which firms can compare their data to industry standards. Clearly, a large percentage of Pennsylvania home building firms are behind the curve with regard to their knowledge and utilization of standardized cost codes.

\section{AUTHOR INFORMATION}

Dr. Mark Law is an Associate Professor of Accounting at Bloomsburg University of Pennsylvania. He received his Ph.D. from the Pennsylvania State University and is a licensed Certified Public Accountant. His career began in public accounting as a staff accountant before he established and developed an accounting and computer consulting practice prior to moving into academia. His research interests include the areas of accounting information systems, construction technology, and emotional intelligence. 


\section{REFERENCES}

1. Bredillet, C. N. (2003). Genesis and role of standards: theoretical foundations and -socio-economical model for the construction and use of standards. International Journal of Project Management, 21(6), 463-470.

2. Kumaraswamy, M. M., \& Dissanayaka, S. M. (2000). ISO 9000 and beyond: from a Hong Kong construction perspective. Construction Management and Economics, 18(7), 783-796.

3. Miller, K. R. (2001). Evaluating electronic documents and data transfer from construction estimating. Dissertation Abstracts International, 62(01), (UMI No. 3002837)

4. Moatazed-Keivani, R., Ghanbari-Parsa, A. R., \& Kagaya, S. (1999). ISO 9000 standards: perceptions and experiences in UK construction industry. Construction Management and Economics, 17(1), 107-119.

5. Gann, D. M. (1996). Construction as a manufacturing process? Similarities and differences between industrialized housing and car production in Japan. Construction Management and Economics, 14(5), 437450.

6. Gibb, A. G. F. (2001). Standardization and pre-assembly - distinguishing myth from reality using case studies. Construction Management and Economics, 19(3), 307-315.

7. Gibb, A. G. F. \& Isack, F. (2001). Client drivers for construction projects: implications for standardization. Engineering, Construction and Architectural Management, 8(1), 46-58.

8. Paulson, B. C. (1995). Computer Applications in Construction. New York: McGraw-Hill.

9. Salem Hiyassat, M. A. (2000). Applying the ISO standards to a construction company: A case study. International Journal of Project Management, 18(4), 275-280. 